\title{
Workability Analysis of Steel Fiber Reinforced Concrete Using Slump and Ve-Be Test
}

\author{
Antonio Domingues de Figueiredo ${ }^{*}$, Marcos Roberto Ceccato $^{b}$ \\ ${ }^{a}$ Escola Politécnica, Universidade de São Paulo - USP, \\ CP 61548, CEP 05508-900, São Paulo, SP, Brazil \\ ${ }^{b}$ Trima Engenharia e Consultoria, Rua Jacob Bereck Steinberg, 446, \\ Jardim Chapadão, Campinas, SP, Brazil
}

Received: August 9, 2015; Revised: October 5, 2015

\begin{abstract}
This works present an experimental study addressing the workability of fiber reinforced concrete (FRC). Only conventional measurements, such as slump and Ve-Be test, were used to evaluate the effect of the fiber content in the mixture. The fiber content shows to be of great influence in the concrete mobility reducing the slump and increasing exponentially the Ve-Be time. The fibers act as a barrier to coarse aggregates movement reducing the materials mobility. So, increasing the aggregate size or the fiber aspect ratio the flowability of the material will be reduced. In order to reduce that effect, an increase in the mortar content and/or in the initial slump could provide better workability conditions. The results showed that the Ve-Be test is not applicable to concrete with plastic consistency. On the other hand, slump test could not be adequate for stiff concretes that will be consolidated by intense vibration.
\end{abstract}

Keywords: fiber reinforced concrete, steel fibers, workability, mix design parameters

\section{Introduction}

The fiber acts as a structural reinforcement for concrete, serving as a bridge for stress transfer in the cracks that may appear in the concrete matrix. Thus, the concrete brittle behavior is replaced by a non-brittle fracture related to a post-cracking bearing capacity ${ }^{1}$. So, the steel fibers are being increasingly employed in industrial floors, road pavements, and tunnel and channels linings, among other applications. One of the main reasons for this increasing use is the possibility of replacing entirely or partially the conventional reinforcement in structural applications ${ }^{2}$, which brings benefits such as labor saving and cracking control.

Despite various improvements in the mechanical properties of hardened concrete, the use of fibers reduces the fluidity of the material ${ }^{3}$, which can cause negative impact in the workability of the concrete. The fiber may cause difficulties for fresh concrete mixing, handling, placing and consolidation. One of the difficulties provided by fibers in mixing process is the fiber ball production that generates lack of homogeneity and reduction in the fiber reinforced concrete (FRC) performance ${ }^{4}$. During application, the fiber could turn more difficult to cast the elements, demanding more labor time due to the lack of fluidity. Also, the fibers could turn problematic to provide good finishing to FRC when they get concentrated on the surface. Coincidentally, the main aspects of the fibers that contribute most to the mechanical performance of the composite are those that bring difficulties to workability, which are the content and the aspect ratio (ratio between fiber length and the diameter of the circle with area equal to the cross section of the fiber). So, it is frequent to affect negatively the fluidity of the material when the engineers are trying to improve the

*e-mail: antonio.figueiredo@usp.br hardened properties of concrete ${ }^{5}$. This fact occurs because the fiber affects the relative mobility of coarse aggregate particles due to the dimensional compatibility between both. So, as higher is the volume and fiber length as difficult became the relative movement between the coarse aggregates and the movement of the mixture in consequence. Also, there is a recommendation in order to use fibers with a length exceeding twice the maximum size of coarse aggregate aiming to enhancement the post-crack strength ${ }^{6}$. Therefore, the feasible fiber consumption, in terms of applicability of the mixture, will be restrained by the amount of coarse aggregate $^{7}$. A strategy to minimize this negative impact could be to increase the matrix mortar content, which corresponds to augment of the actual volume in which the fiber is effectively incorporated. So, studies on the factors that obstruct the applicability of FRC are needed ${ }^{8}$.

In the international literature of the last decades, there are several studies that evaluate the influence of the addition of fibers in the workability through traditional test methods ${ }^{5,9,10}$. However, these works had emphasized only the influence of high content levels of steel fiber (between $1 \%$ and $4 \%$ by volume). That condition is not the common situation for the majority of FRC applications in Brazil ${ }^{1}$. These high volumes of fiber are applicable just when a strain-hardening behavior is requested for the composite ${ }^{2}$. So, there is a need in studies focusing lower content of fibers (up to $1 \%$ by volume) designate to applications where strain-softening or slight strain-hardening behavior is adequate as the FRC for pavements and tunnel linings.

The analysis of the impact of the fibers in the FRC workability was also addressed in some previous research focusing on self-compacting FRC ${ }^{11-13}$ or FRC with lightweight aggregate $^{14,15}$. All these works were based on conventional 
evaluations to measure workability as the slump, slump-flow and V-funnel tests, for example. Other researchers used rheometers to assess the FRC fresh behavior. The studies were limited to ultra-high strength concretes ${ }^{16}$ or mortars ${ }^{17}$ but, up to now, rheometers are not suitable to evaluate the effect of the maximum aggregate size in plastic and especially stiff consistency concretes. This difficulty is associate to the risk of locking the rheometers rackets by the aggregates with greater diameter during the test. However, these kinds of concretes are of interest for such applications as pavements.

Thus, it is necessary the appropriate evaluation the FRC workability concerning the consistency changes provoked by the fiber addition. Thus, evaluating the available methods, two relevant test methods were identified. These are the slump test ${ }^{18}$ and Ve-Be test ${ }^{19}$. Previous studies ${ }^{20}$ demonstrated that the inverted cone test ${ }^{21}$ is not adequate when one wants to evaluate the workability of FRC. This fact could explain the reason that the standard related to this test method was discontinued. So, it was disregarded in this work. On the other hand, the study conducted by Laskar ${ }^{22}$ indicates that the Ve-Be test could be useful for FRC, although the fiber content was too reduced ( $1.5 \%$ by weight). Thus, this study aims to evaluate some of the basic parameters FRC with low fiber content and plastic consistency using test methods available and compatible with this condition.

\section{Metodology}

The initial consistency of concrete (before the addition of the fibers), the maximum size of coarse aggregate, the dry mortar content, the aspect ratio and the fiber content were selected as independent variables for this experimental study. The initial consistency of the material is important because it is the main control parameter for many FRC applications. Thus, this experimental program aims to parameterize the impact of fiber in the slump, measure by the Brazilian standard method ABNT NBR NM 67: 1998 ${ }^{18}$. When the FRC reach a stiff consistency with the augment of fiber content, the workability will be parameterized by the use of Ve-Be test ${ }^{19}$. To facilitate the study of these selected variables were organized in four groups, depending on the variable that was assessed. Table 1 shows the four groups of analysis and the independent variables values.

High early strength cement (CP V type according to the Brazilian standard ABNT NBR 5733-EB2:1991 ${ }^{[23]}$ ) was used in the experimental program. The characteristics of this cement are presented in Table 2 . The aggregates used were a river sand and two crushed granite tones with two different sizes. The characteristics of these aggregates are presented in Table 3. Two admixtures were also used in the experiment. The first one was a water reducing and retardant that fits the requirement of the Brazilian standard ABNT NBR 11768: 2011 (type $\mathrm{PR}^{[24]}$ ). The second one was a setting inhibitor admixture (Delvocrete). The use of this retardant admixture was due to the extra time provided before initial setting. So, there was enough time to manipulate the material without any loss of fluidity provoked by the material hydration reactions. This admixture was dosed to inhibit the setting reactions for eight hours, given enough time to complete all procedures.

The three fibers selected for the study were of circular cross section and with hook ends corresponding to the type
Table 1. Mixture groups organized according to the independent variables used in the study.

\begin{tabular}{|c|c|}
\hline \multicolumn{2}{|c|}{ Influence of initial consistency } \\
\hline Variable & Values \\
\hline Initial consistency & $5,10,15,20 \mathrm{~cm}$ \\
\hline Aspect ratio & 80 \\
\hline Coarse aggregate diameter & $19 \mathrm{~mm}$ \\
\hline $\begin{array}{l}\text { Dry mortar content in } \\
\text { weight }(\alpha)\end{array}$ & $50 \%$ \\
\hline Fiber volume & $0,0.26,0.51,0.77,1.03,1.28 \%$ \\
\hline Fiber consumption & $0,20,40,60,80,100 \mathrm{~kg} / \mathrm{m}^{3}$ \\
\hline GRUP 2: & ce of fiber aspect ratio26 \\
\hline Variable & Values \\
\hline Initial consistency & $10 \mathrm{~cm}$ \\
\hline Aspect ratio & $60,80,100$ \\
\hline Coarse aggregate diameter & $19 \mathrm{~mm}$ \\
\hline $\begin{array}{l}\text { Dry mortar content in } \\
\text { weight }(\alpha)\end{array}$ & $50 \%$ \\
\hline Fiber volume & $0,0.26,0.51,0.77,1.03,1.28 \%$ \\
\hline $\begin{array}{l}\text { Equivalent fiber } \\
\text { consumption }\end{array}$ & $0,20,40,60,80,100 \mathrm{~kg} / \mathrm{m}^{3}$ \\
\hline Influence of & oarse aggregate maximum size \\
\hline Variable & Values \\
\hline Initial consistency & $10 \mathrm{~cm}$ \\
\hline Aspect ratio & 80 \\
\hline Coarse aggregate diameter & $9.5 \mathrm{~mm}, 19 \mathrm{~mm}$ \\
\hline $\begin{array}{l}\text { Dry mortar content in } \\
\text { weight }(\alpha)\end{array}$ & $50 \%$ \\
\hline Fiber volume & $0,0.26,0.51,0.77,1.03,1.28 \%$ \\
\hline $\begin{array}{l}\text { Equivalent fiber } \\
\text { consumption }\end{array}$ & $0,20,40,60,80,100 \mathrm{~kg} / \mathrm{m}^{3}$ \\
\hline
\end{tabular}

GRUP 4: Influence of dry mortar content in the matrix

\begin{tabular}{lc}
\hline \multicolumn{1}{c}{ Variable } & Values \\
\hline Initial consistency & $10 \mathrm{~cm}$ \\
Aspect ratio & 80 \\
Coarse aggregate diameter & $19 \mathrm{~mm}$ \\
$\begin{array}{l}\text { Dry mortar content in } \\
\text { weight }(\alpha)\end{array}$ & $50 \%$ and $55 \%$ \\
Fiber volume & $0,0.26,0.51,0.77,1.03,1.28 \%$ \\
$\begin{array}{l}\text { Equivalent fiber } \\
\text { consumption }\end{array}$ & $0,20,40,60,80,100 \mathrm{~kg} / \mathrm{m}^{3}$ \\
\hline
\end{tabular}

Table 2. Chemical and physical characteristics of the cement used in the study.

\begin{tabular}{|c|c|c|c|}
\hline \multicolumn{3}{|c|}{ Tests } & Results \\
\hline \multirow{7}{*}{ Physical } & \multicolumn{2}{|c|}{$\# 200(\%)$} & 0.1 \\
\hline & \multicolumn{2}{|c|}{ Fineness Blaine $\left(\mathrm{m}^{2} / \mathrm{kg}\right)$} & 462.0 \\
\hline & \multicolumn{2}{|c|}{ Initial setting time (minutes) } & 123 \\
\hline & \multirow{4}{*}{$\begin{array}{l}\text { Compressive } \\
\text { strength }(\mathrm{MPa})\end{array}$} & 1 day & 18.0 \\
\hline & & 3 days & 42.2 \\
\hline & & 7 days & 46.6 \\
\hline & & 28 days & 55.7 \\
\hline \multirow{5}{*}{ Chemical } & \multicolumn{2}{|c|}{$\mathrm{CO}_{2}(\%)$} & 2.03 \\
\hline & \multicolumn{2}{|c|}{$\mathrm{SO}_{3}(\%)$} & 2.71 \\
\hline & \multicolumn{2}{|c|}{$\mathrm{MgO}(\%)$} & 0.60 \\
\hline & \multicolumn{2}{|c|}{ Loss on ignition at $1000{ }^{\circ} \mathrm{C}(\%)$} & 2.73 \\
\hline & \multicolumn{2}{|c|}{ Insoluble residue (\%) } & 0.41 \\
\hline
\end{tabular}


Table 3. Physical characteristics of the aggregates used in the study.

\begin{tabular}{|c|c|c|c|c|c|}
\hline \multicolumn{3}{|c|}{ Tests } & \multicolumn{3}{|c|}{ Material } \\
\hline \multirow{13}{*}{$\begin{array}{l}\text { Particle size } \\
\text { distribution }\end{array}$} & \multirow{12}{*}{ Retained material (\%) } & Sieve size $(\mathrm{mm})$ & Fine aggregate & Coarse aggregate 1 & Coarse aggregate 2 \\
\hline & & 19.0 & - & - & 2.4 \\
\hline & & 12.5 & - & 0.3 & 53.3 \\
\hline & & 9.5 & - & 4.0 & 31.6 \\
\hline & & 6.3 & - & 62.1 & 10.6 \\
\hline & & 4.8 & 1.5 & 19.2 & 1.3 \\
\hline & & 2.4 & 3.9 & $14.1 *$ & $2.7 *$ \\
\hline & & 1.2 & 8.8 & - & - \\
\hline & & 0.6 & 27.9 & - & - \\
\hline & & 0.3 & 33.1 & - & - \\
\hline & & 0.15 & 21.6 & - & - \\
\hline & & $<0.15$ & 3.3 & - & - \\
\hline & \multicolumn{2}{|l|}{ Fineness modulus } & 2.35 & 5.90 & 6.85 \\
\hline \multicolumn{3}{|c|}{ Specific gravity $\left(\mathrm{kg} / \mathrm{m}^{3}\right)$} & 2.62 & 2.64 & 2.62 \\
\hline
\end{tabular}

A1 of the Brazilian standard ${ }^{25}$. All of the fibers had only one fixed length and the diameter varied from one to another. So, the fibers used have different aspect ratios depending on the variation of its diameter, as shown in Table 4. These fibers were provided collated as presented in Figure 1. This condition helps to avoid clusters and turn easier the dispersion in the $\operatorname{mix}^{1}$.

A regular mixer, with inclined axis and 150 liters in capacity, was used to mix the materials. The first materials introduced in the mixer were the aggregates in the dry state together with $30 \%$ of water and mixed for 30 seconds. Then the cement was added together with the remaining water containing the admixtures (plasticizer and setting inhibitor). In the sequence, the mixer was restarted and the mixture procedure takes 3 minutes. The plasticizer content was adjusted to obtain a slump value for each specified mix. The materials were storage in the laboratory previously to the mixture production that occurred in the laboratory room temperature of $23 \pm 2{ }^{\circ} \mathrm{C}$.

All the mixtures were submitted to the slump and Ve-Be tests, primarily for the concretes without fibers. At this moment the initial slump was measured. Then the controlled amounts of fibers were successively added in the same mixtures in order to reach the different fiber contents proposed for the study. The Ve-Be and slump test were repeated after every fiber content increment. So, the same matrix mixture was considered for all evaluations of the consistency influenced by the fiber amount.

Table 5 shows the composition and some characteristics of concrete of each group of analysis as obtained in the experimental program. The concrete mix design follows the recommendations for FRC with plastic consistency levels ${ }^{1}$. Table 5 also present the plasticizer admixture content adjusted to correct the initial slump for each mix series.

\section{Results and Analysis}

The results obtained in the slump and Ve-Be tests for the various mixture series studied are shown in Table 6 . As expected, there were reductions for all slump values with increased fiber content ${ }^{9,10}$. Figure 2 presents a correlation
Table 4. Characteristics of the fibers used in the experiment.

\begin{tabular}{cccc}
\hline Fiber & Length $(\mathbf{m m})$ & Diameter $(\mathbf{m m})$ & Aspect ratio \\
\hline AR60 & 60 & 1.00 & 60 \\
AR80 & 60 & 0.75 & 80 \\
AR100 & 60 & 0.60 & 100 \\
\hline
\end{tabular}

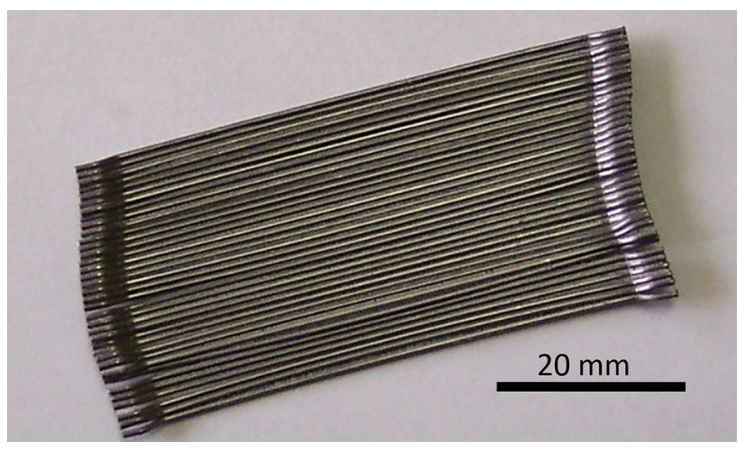

Figure 1. Example of glued fiber used in the experiment.

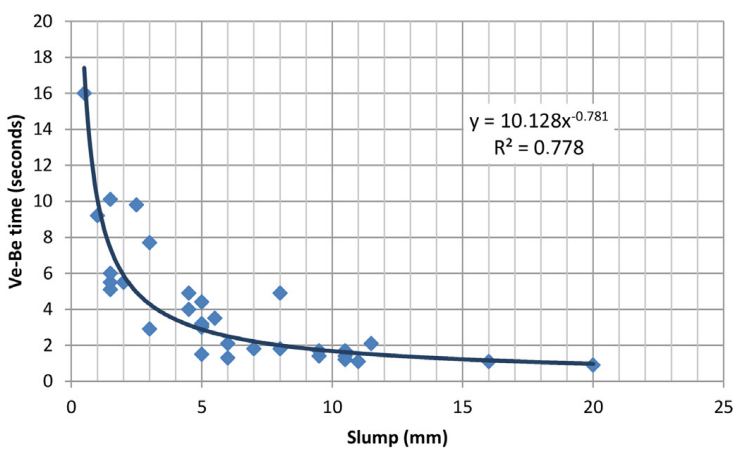

Figure 2. Correlation between all the slump values higher than zero and the Ve-Be time.

between all the obtained results, except the results were the slump value was zero. The reason to exclude the null values of slump is the fact that the test reached the limit of measurement capacity at this condition. In Figure 2 is possible to observe that when the slump value is higher than $10 \mathrm{~mm}$ 
Table 5. Composition and characteristics of each mixture series of the experiment.

\begin{tabular}{|c|c|c|c|c|c|c|c|c|c|c|}
\hline Group & $\begin{array}{l}\text { Code of } \\
\text { mixture }\end{array}$ & $\begin{array}{c}\text { Mixture } \\
\text { proportion } \\
(1: \text { fa:ca)(I) }\end{array}$ & $\begin{array}{c}w / c \\
\text { ratio }\end{array}$ & $\begin{array}{c}\text { Dry } \\
\text { mortar } \\
\text { proportion } \\
(\%)\end{array}$ & $\begin{array}{c}\text { Total } \\
\text { amount } \\
\text { of water } \\
\text { (II) (\%) }\end{array}$ & $\begin{array}{c}\text { Cement } \\
\text { consumption } \\
\left(\mathrm{kg} / \mathrm{m}^{3}\right)\end{array}$ & $\begin{array}{l}\text { Maximum } \\
\text { aggregate } \\
\text { size }(\mathrm{mm})\end{array}$ & $\begin{array}{c}\text { Fiber } \\
\text { aspect } \\
\text { ratio }\end{array}$ & $\begin{array}{l}\text { Plasticizer } \\
\text { dosage } \\
\text { (\%) (III) }\end{array}$ & $\begin{array}{l}\text { Defined } \\
\text { slump } \\
\text { (cm) }\end{array}$ \\
\hline \multirow{4}{*}{1} & slump 5 & \multirow{4}{*}{$1: 2.21: 3.21$} & \multirow{4}{*}{0.50} & \multirow{4}{*}{50} & \multirow{4}{*}{7.8} & \multirow{4}{*}{350} & \multirow{4}{*}{19} & \multirow{4}{*}{80} & 0.2 & $5 \pm 1$ \\
\hline & slump 10 & & & & & & & & 0.3 & $10 \pm 1$ \\
\hline & slump 15 & & & & & & & & 1 & $15 \pm 1$ \\
\hline & slump 20 & & & & & & & & 0.9 & $20 \pm 1$ \\
\hline \multirow{3}{*}{2} & AR 60 & \multirow{3}{*}{$1: 2.21: 3.21$} & \multirow{3}{*}{0.50} & \multirow{3}{*}{50} & \multirow{3}{*}{7.8} & \multirow{3}{*}{350} & \multirow{3}{*}{19} & 60 & 0.3 & \multirow{3}{*}{$10 \pm 1$} \\
\hline & AR 80 & & & & & & & 80 & 0.3 & \\
\hline & AR 100 & & & & & & & 100 & 0.7 & \\
\hline \multirow{2}{*}{3} & a19 mm & \multirow{2}{*}{$1: 2.21: 3.21$} & 0.50 & \multirow{2}{*}{50} & \multirow{2}{*}{8.11} & 350 & 19 & \multirow{2}{*}{80} & 0.3 & \multirow{2}{*}{$10 \pm 1$} \\
\hline & a9.5 mm (IV) & & 0.52 & & & 347 & 9.5 & & 2.1 & \\
\hline \multirow{2}{*}{4} & $\alpha 50$ & $1: 2.21: 3.21$ & \multirow{2}{*}{0.50} & 50 & \multirow{2}{*}{7.8} & \multirow{2}{*}{350} & \multirow{2}{*}{19} & \multirow{2}{*}{80} & 0.3 & \multirow{2}{*}{$10 \pm 1$} \\
\hline & $\alpha 55$ & $1: 2.53: 2.88$ & & 55 & & & & & 0.6 & \\
\hline
\end{tabular}

(I) Is the weight proportion used in the mixture: 1 is one $\mathrm{kg}$ of cement, fa is the mass proportion of fine aggregate for $1 \mathrm{~kg}$ of cement, and ca is the mass proportion of coarse aggregate for $1 \mathrm{~kg}$ of cement. (II) Percentage relative to the total dry materials weight. (III) Percentage relative to the cement weight. (IV) This mixture required extra amount of water during mixing in order to achieve the slump of $10 \mathrm{~cm}$. Consequently the w/c ratio and the cement consumption had changed.

Table 6. Results obtained in the slump and Ve-Be tests.

\begin{tabular}{|c|c|c|c|c|c|c|c|c|}
\hline \multicolumn{9}{|c|}{ Slump value (cm) } \\
\hline $\begin{array}{c}\text { Fiber } \\
\text { volume }(\%)\end{array}$ & SLUMP5 & $\begin{array}{c}\text { AR80 } \\
\text { A19mm } \\
\alpha 50\end{array}$ & SLUMP15 & SLUMP20 & AR100 & AR60 & A9.5 $\mathrm{mm}$ & $\alpha 55$ \\
\hline 0 & 5.0 & 11.0 & 16.0 & 20.0 & 10.5 & 9.5 & 9.5 & 10.5 \\
\hline 0.26 & 3.0 & 5.0 & 11.5 & 10.5 & 4.5 & 7.0 & 6 & 6.0 \\
\hline 0.51 & 1.5 & 1.5 & 8.0 & 8.0 & 0.5 & 5.0 & 5.5 & 5.0 \\
\hline 0.77 & 0.0 & 0.0 & 2.5 & 5.0 & 0.0 & 2.0 & 4.5 & 1.5 \\
\hline 1.03 & - & - & 0.0 & 1.5 & - & 1.0 & 3 & 0.0 \\
\hline 1.28 & - & - & - & 0.0 & - & 0.0 & 0 & - \\
\hline \multicolumn{9}{|c|}{ Ve-Be (s) } \\
\hline $\begin{array}{c}\text { Fiber } \\
\text { volume (\%) }\end{array}$ & SLUMP5 & $\begin{array}{c}\text { SLUMP10 } \\
\text { AR80 } \\
\text { A19mm } \\
\alpha 50\end{array}$ & SLUMP15 & SLUMP20 & AR100 & AR60 & A9.5 $\mathrm{mm}$ & $\alpha 55$ \\
\hline 0 & 1.5 & 1.1 & 1.1 & 0.9 & 1.4 & 1.4 & 1.7 & 1.7 \\
\hline 0.26 & 2.9 & 3.0 & 2.1 & 1.2 & 4.9 & 1.8 & 2.1 & 1.3 \\
\hline 0.51 & 5.1 & 5.5 & 4.9 & 1.8 & 16.0 & 3.1 & 3.5 & 3.2 \\
\hline 0.77 & 10.2 & 11.3 & 9.8 & 4.4 & 73 & 5.5 & 4 & 6 \\
\hline 1.03 & 25.8 & 22.2 & 24.0 & 10.1 & 99 & 9.2 & 7.7 & 19 \\
\hline 1.28 & 37.1 & 42.8 & 40.6 & 23.8 & - & 12.9 & 15.6 & 20.8 \\
\hline
\end{tabular}

there is almost no variation in the Ve-Be results. On the other hand, when the slump value tends to zero the Ve-Be time increases exponentially. This fact demonstrates that the Ve-Be test is a more suitable to verify the consistency variation of stiff concretes, not being able to distinguish the plastic concrete behavior as does the slump. On the other hand, if a vibrating system is used to compact a stiff material, the Ve-Be results could be very useful and demonstrate that the slump test have no significance.

Considering only the first group of analysis, where only the fiber with aspect ratio equal to 80 was added to the matrix, there was a progressive increase of consistency with increasing fiber content, as can be seen in Figure 3. The slump loss occurred in a relatively parallel trend with up to a moment that the mixtures tend to have null values. So, as higher is the initial slump of the mixture the higher is the amount of fiber needed to reach zero slump.

The variation of initial slump of the concrete in all groups was between $5 \mathrm{~cm}$ and $20 \mathrm{~cm}$. However, this slump variation did not provide a significant difference in the results obtained by the Ve-Be test (Figure 4). The Ve-Be test was more effective to assess the impact of fiber adding especially when the highest fiber consumptions are applied. The mixtures presented a stiff consistency and the slump test was not suitable to distinguish the mixtures behaviors when the fiber volume was higher than $0.77 \%$ (equivalent to a fiber consumption of $60 \mathrm{~kg} / \mathrm{m}^{3}$ ). The behaviors of almost all mixtures were very similar with no significant variation 
for the Ve-Be results. The exception is the mixture with the initial slump of $20 \mathrm{~cm}$ that presented a reduced Ve-Be time. However, the SLUMP20 results should be considered with some restrictions since it had presented a large exudation, which may have substantially changed the response the material and the results of Ve-Be test. Thus, regardless of the initial slump level, increasing the fiber content will turn difficult the mobility of the mixtures, especially when a low level of energy is applied for the concrete consolidation. As expected, the mixture will be much stiffer when higher fiber consumption is applied. However, higher levels of initial slump facilitate the overall mobility of the mixture at low shear rates and this implies a lower loss to the FRC workability in such circumstances.

Group 1 results put in evidence that single point tests (where just one level of shear rate is applied as it occurs with Ve-Be and slump tests) could not be enough to widely characterize the workability of the FRC. For example, there is a great difference in the slump results of mixtures SLUMP10 and SLUMP15 when the fiber volume used was $0.51 \%\left(40 \mathrm{~kg} / \mathrm{m}^{3}\right)$ resulting $1.5 \mathrm{~cm}$ and $8.0 \mathrm{~cm}$, respectively. Concomitantly, the Ve-Be test presented a very small difference corresponding to 5.5 and 4.9 seconds to SLUMP10 and SLUMP15, respectively. So, this finding could lead to infer that differences in the FRC slump level will not necessarily affected the material compaction when greater external vibration energy is used.

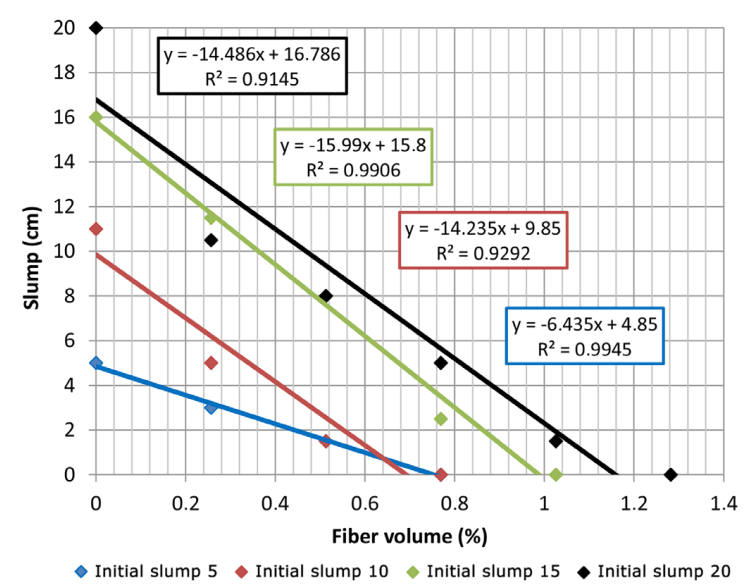

Figure 3. Effect of the fiber content increase in the slump of the concretes with different initial slump level.

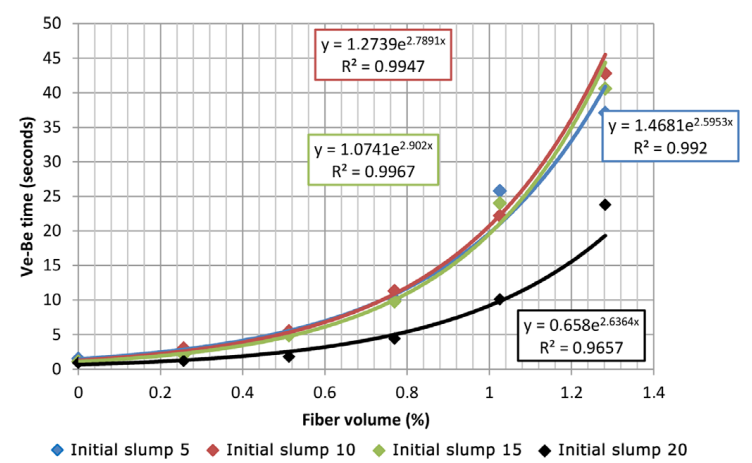

Figure 4. Exponential correlations between Ve-Be time and fiber content of the concretes with different initial slump level.
The influence of the fibers aspect ratio in the fresh concrete behavior was observed through both tests (Figures 5 and 6). The reduction of the diameter of the fiber, which increased its aspect ratio, leads to an increased number of fibers per unit volume of FRC. This situation produces increasing difficulty to the coarse particles movement, restricting the mobility of the mixture. This can lead to a loss of workability turning the compaction process much more difficult. Thus, superior fiber aspect ratios have led to a faster reduction in the slump value with the increase in the fiber content. However, the impact on the Ve-Be results were even more intense, indicating that even with the use of vibration, the material mobility was severely reduced increasing the compaction time. Thus, the fiber with greater aspect ratio (AR100) causes higher difficulty to compaction when its volume exceeds $0.51 \%\left(40 \mathrm{~kg} / \mathrm{m}^{3}\right)$ compared to the fiber with aspect ratio of 60 , which provoked a less intense reduction in the Ve-Be time. The difficulty of handling the fiber with aspect ratio of 100 was so great that turns impossible to perfectly mix the material when the fiber volume was $1.28 \%\left(100 \mathrm{~kg} / \mathrm{m}^{3}\right)$. Thus, the compaction of concrete was much easier when fiber with low aspect ratio was used, as expected.

To prove that the loss of mobility of the mixture is associated with increased difficulty of relative movement of larger particles, the effect of the maximum size of coarse aggregate was also evaluated. The concrete with aggregates with maximum size of $9.5 \mathrm{~mm}$ obtained a lower loss of slump (Figure 7) and also a lower increase in the Ve-Be time (Figure 8 ) with the increased fiber content. There was also

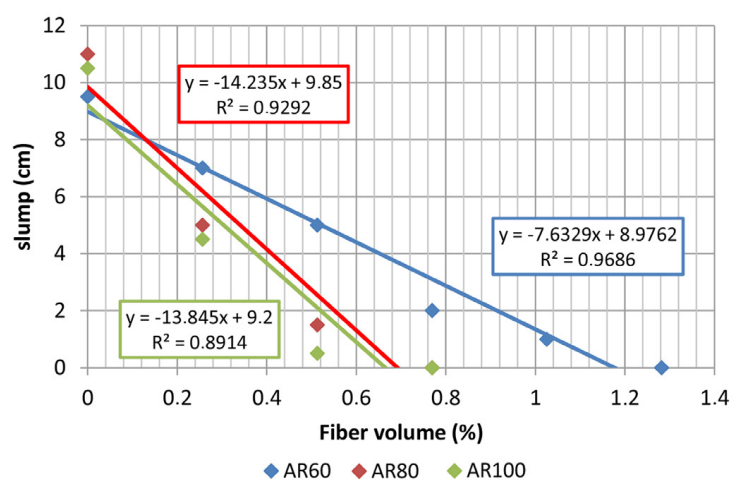

Figure 5. Effect of the fiber aspect ratio in the slump of the concrete.

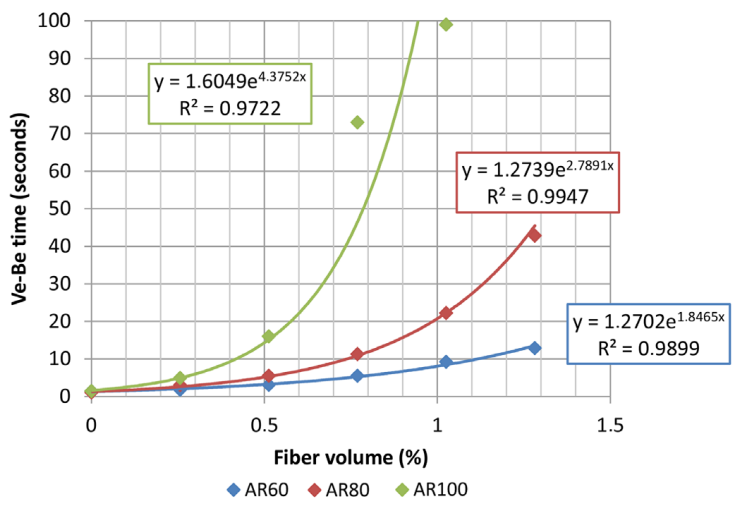

Figure 6. Exponential correlations between Ve-Be time and fiber content of the concretes with different aspect ratio of the fibers. 


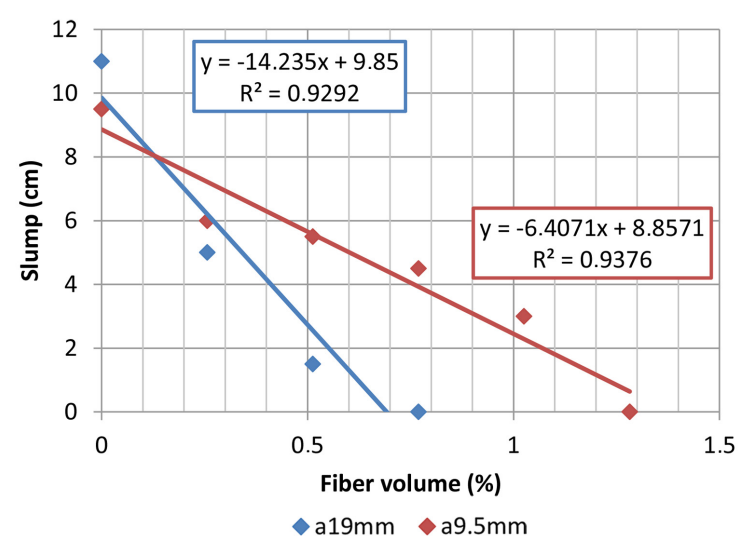

Figure 7. Effect of the fiber content increase in the slump of the concretes with different coarse aggregate sizes.

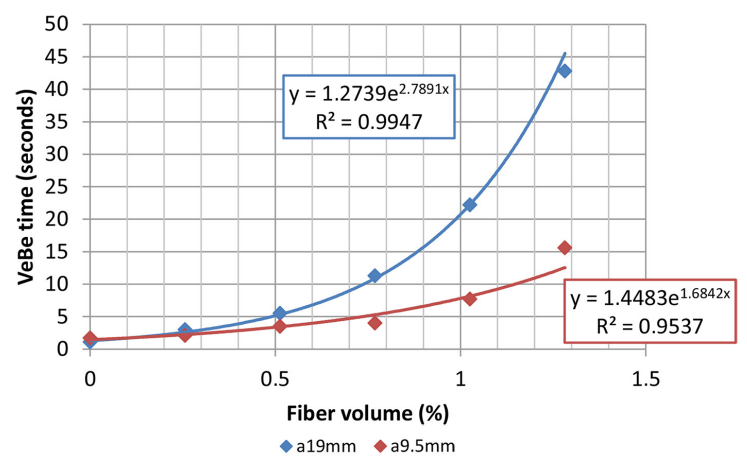

Figure 8. Exponential correlations between Ve-Be time and fiber content of the concretes with different coarse aggregate sizes.

a more homogeneous distribution of the fibers in all fiber contents. The concrete with coarser aggregate showed a more intense impact in both measurements with the increase in the fiber content. In addition, there were fibers balls when the fiber volume content was greater than $0.77 \%\left(60 \mathrm{~kg} / \mathrm{m}^{3}\right)$, which had to be handled. It is possible to observe that the behavior of concrete with small aggregates presented a very similar pattern to the concrete reinforce with the fiber with smaller aspect ratio (AR60 in Figure 6). So, this fact demonstrates that the difficulty of relative movement of the particles may be decreased by reducing the number of fibers or by reducing the size of the aggregate.

One of the important parameters in traditional concrete mix design is the definition of dry mortar content. The higher is the mortar content, the lower is the relative coarse aggregate volume. By the way, the fiber occupies the volume corresponding to the mortar in concrete and, the larger is the coarse aggregate content, the lower is the volume available for the fiber in the mixture. This is reflected in the results presented in Figures 9 and 10 for the slump and Ve-Be tests, respectively. The higher dry mortar content provided a smaller reduction in the slump level or lower increase in the Ve-Be time with increased fiber content. The dry mortar content of $50 \%$ corresponds to a $42.6 \%$ of the volume of concrete occupied by the coarse aggregate leaving a minimum of $57.4 \%$ of the concrete volume available for the fiber, not considering the entrapped air. On the other hand, the dry

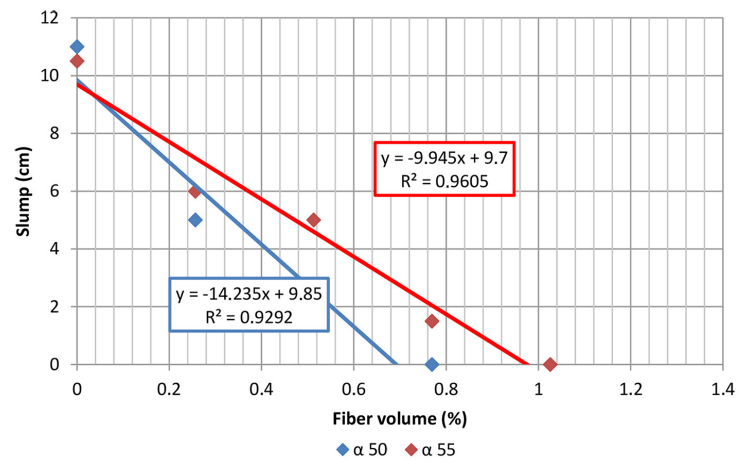

Figure 9. Effect of the fiber content increase in the slump of the concretes with different mortar contents.

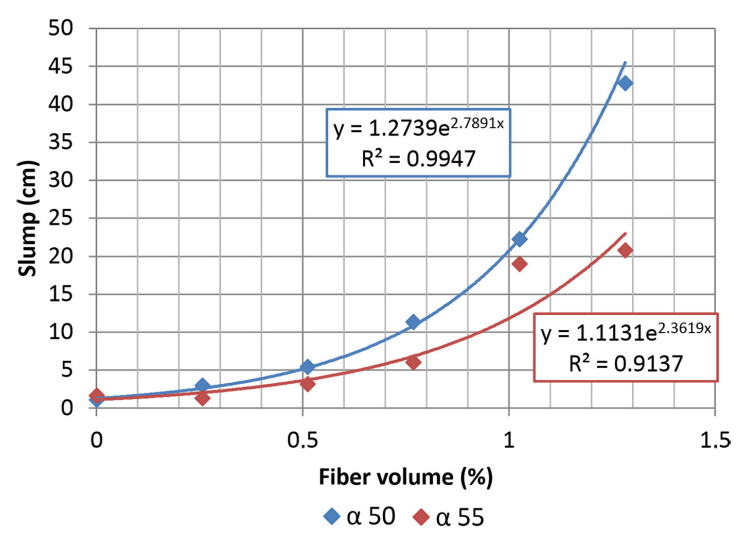

Figure 10. Exponential correlations between Ve-Be time and fiber content of the concretes with different mortar content.

mortar content of $55 \%$ provided at least $62.2 \%$ of the concrete volume to the fibers. So, the greater volume of mortar in the concrete permits a greater spacing between fibers and facilitates the relative movement between the particles. It is possible to figure out that, when the fiber volume content reached $1.03 \%\left(80 \mathrm{~kg} / \mathrm{m}^{3}\right)$, the slump test was no longer able to measure the impact of the addition of fiber in the mobility of the material. It is important to notice that the concrete with higher volume of mortar offers a better condition for mixing, avoiding fibers balls, and providing a better homogeneity for the mixtures as a consequence. Moreover, the concrete with higher volume of mortar presented a similar behavior to the concretes with smaller aggregates or fibers with lower aspect ratio. This indicates that the improvement in FRC workability could be achieved using fibers with lower larger aspect ratio. But, as this solution will lead to a reduction in the post-crack strength, it is recommended to increase the mortar content and reduce the size of the coarse aggregate to accomplish the same workability condition using the same fiber type.

\section{Conclusions}

Based on the previous discussion of the results, it can be concluded that the addition of fibers in plastic concrete changes its mobility, even if these content levels are lower than those studied in previous works. The loss of mobility occurs primarily by the fibers blocking the relative movement 
of the aggregates which is less intense when reducing the aspect ratio of the fiber, which provoke reduction of hardened FRC post-crack strength. A better solution could be achieved reducing the maximum size of the aggregate or increasing the mortar content in the concrete. Thus, the use of an appropriate mix design method, considering the effect of the fibers, is needed to guarantee adequate workability conditions for FRC.

Although the limitations of the experimental program of this work, is possible to affirm that the results showed that the Ve-Be test is not applicable to conditions in which the concrete is more fluid and its slump exceeds $100 \mathrm{~mm}$. This condition typically occurs for lower volume of fibers, below $0.7 \%$ by volume $\left(55 \mathrm{~kg} / \mathrm{m}^{3}\right)$. On the other hand, for

\section{References}

1. Figueiredo AD. Concreto reforçado com fibras. [Tese de LivreDocência]. São Paulo: Universidade de São Paulo; 2011.

2. di Prisco M, Plizzari G and Vandewalle L. Fibre reinforced concrete: new design perspectives. Materials and Structures. 2009; 42(9):1261-1281. http://dx.doi.org/10.1617/s11527-0099529-4.

3. Bentur A and Mindess S. Fibre reinforced cementitious composites. New York: Taylor \& Francis; 2007.

4. American Society for Testing and Materials - ASTM. ASTM C1116: standard specification for fiber-reinforced concrete. Philadelphia: ASTM; 2015. Book of ASTM Standards, pt. 04.02 .

5. Hannant DJ. Fibre cements and fibre concretes. Chichester: John Wiley; 1978.

6. Maidl B. Stahlfaserbeton. Berlin: Ernst \& Sohn Verlag für Architektur und technische Wissenschaften; 1991.

7. Mangat PSE and Swamy RN. Compactibility of steel fibre reinforced concrete. Concrete (London). 1974; 8(5):34-35.

8. Balaguru PN and Shah SP. Fiber reinforced cement composites. USA: McGraw-Hill; 1992.

9. Johnston CD. Measures of the workability of steel fiber reinforced concrete and their precision. Cement, Concrete, and Agregates. 1984; 6(2):74-83.

10. Soroushian P and Bayasi Z. Fiber type effects on the performance of steel fiber reinforced concrete. ACI Materials Journal. 1991; 88(2):129-134

11. Sahmaran M, Yurtseven A and Yaman IO. Workability of hybrid fiber reinforced self-compacting concrete. Building and Environment. 2005; 40(12):1672-1677. http://dx.doi. org/10.1016/j.buildenv.2004.12.014.

12. Ferrara L, Park Y-D and Shah SP. A method for mix-design of fiber-reinforced self-compacting concrete. Cement and Concrete Research. 2007; 37(6):957-971. http://dx.doi.org/10.1016/j. cemconres.2007.03.014.

13. Ding Y, Liu S, Zhang Y and Thomas A. The investigation on the workability of fibre cocktail reinforced self-compacting high performance concrete. Construction \& Building Materials. 2008; 22(7):1462-1470. http://dx.doi.org/10.1016/j. conbuildmat.2007.03.034. fiber contents above this value, the slump applicability is much more difficult. It is possible that even when the slump test is showing some variations this fact will not produce different Ve-Be time results. This may indicate that variations in certain low level of slump may not mean bad compaction condition for the concrete compacted under intense vibration. In contrast, the Ve-Be test was able to demonstrate differences in fresh behavior of stiff concretes which were not detectable by the slump. There are some applications where this kind of concrete is desirable as is the case of dry-cast concretes elements. Both test methods, in its limitations, allowed evaluating the effect of the fiber in the fresh concrete when it was not possible to use most comprehensive tests, such as the rheometers.

14. Swamy N and Jojagha AH. Workability of steel fibre reinforced lightweight aggregate concrete. The International Journal of Cement Composites and Lightweight Concrete. 1982; 4(2):103109.

15. Chen B and Liu J. Contribution of hybrid fibers on the properties of the high-strength lightweight concrete having good workability. Cement and Concrete Research. 2005; 35(5):913-917. http:// dx.doi.org/10.1016/j.cemconres.2004.07.035.

16. Martinie L, Rossi P and Roussel N. Rheology of fiber reinforced cementitious materials: classification and prediction. Cement and Concrete Research. 2010; 40(2):226-234. http://dx.doi. org/10.1016/j.cemconres.2009.08.032.

17. Kuder KG, Ozyurt N, Mu EB and Shah SP. Rheology of fiber-reinforced cementitious materials. Cement and Concrete Research. 2007; 37(2):191-199. http://dx.doi.org/10.1016/j. cemconres.2006.10.015.

18. Associação Brasileira de Normas Técnicas-ABNT. ABNT NBR NM 67:1998: concreto - determinação de consistência pelo abatimento do tronco de cone. Rio de Janeiro: ABNT; 1998.

19. Americam Concrete Institute - ACI. Guide for selecting proportions for no-slump concrete: ACI 211.3R-02. USA: ACI; 2009.

20. Ceccato MR. Estudo da trabalhabilidade do concreto reforçado com fibras de aço. [Dissertation]. São Paulo: Universidade de São Paulo; 1998.98 p.

21. American Society for Testing and Materials-ASTM. ASTM C995: standard test method for time of flow of fiber-reinforced concrete through inverted cone slump. Philadelphia: ASTM; 1994. Book of ASTM Standards, pt. 04.02.

22. Laskar AI. Correlating slump, slump flow, vebe and flow tests to rheological parameters of high-performance concrete. Materials Research. 2009; 12(1):75-81. http://dx.doi.org/10.1590/S151614392009000100009 .

23. Associação Brasileira de Normas Técnicas - ABNT. ABNT NBR 5733:1991: cimento Portland de alta resistência inicial. Rio de Janeiro: ABNT; 1991.

24. Associação Brasileira de Normas Técnicas - ABNT. ABNT NBR 11768:2011: aditivos. Aditivos químicos para concreto de cimento Portland: requisitos. Rio de Janeiro: ABNT; 2011.

25. Associação Brasileira de Normas Técnicas - ABNT. ABNT NBR 15530: 2007: fibras de aço para concreto. Rio de Janeiro: ABNT; 2007. 